\section{Commentary: The tortoise and the hare: Does speed matter in pediatric VAD therapy?}

\author{
Chet R. Villa, MD, and David L. S. Morales, MD
}

The arrival of the HeartWare HVAD (Medtronic, Minneapolis, Minn) had an immediate impact on the pediatric ventricular assist device (VAD) community. The HVAD became the dominant VAD used to support children weighing $\geq 20$ to $25 \mathrm{~kg}$. ${ }^{1}$ Although the use of this device in children is associated with comparable survival to that seen in case-matched young adults, the hemocompatibility and neurologic event rates have room for improvement, especially in children $<20 \mathrm{~kg}{ }^{2,3}$ The potential reasons for the observed event rate are likely multifactorial, but the use of lower pump speeds has been identified as a possible contributor.

In their article in this issue of the Journal, Granegger and colleagues report their clinical observations of elevated lactate dehydrogenase (LDH) and d-dimer in 14 children supported with an HVAD. ${ }^{4}$ Drawing conclusions from their clinical cohort is challenging given the small patient numbers, heterogeneity in anticoagulation management, and nonhemolytic causes of elevated LDH. Nonetheless, the clinical observations of potential elevated hemolysis were used to guide in silico and in vitro analyses of the flow characteristics and hemolysis profile under a variety of potential operating conditions. The in silico analysis suggested that the lower RPM state was associated with adverse changes in device flow fields and shear stress. These lower RPM states were also associated with increased levels of blood trauma in vitro as assessed by the normalized index of hemolysis.

The clinical significance of the changes in flow dynamics and in vitro blood trauma reported by Granegger and colleagues remains unclear. The idealized flow

From the Heart Institute, Cincinnati Children's Hospital Medical Center, Cincinnati, Ohio.

Disclosures: Dr Morales serves as a consultant for Berlin Heart, Medtronic, Abbot, and Syncardia. Dr Villa has nothing to disclose with regard to commercial support.

Received for publication Oct 31, 2019; revisions received Oct 31, 2019; accepted for publication Oct 31, 2019; available ahead of print Jan 8, 2020.

Address for reprints: David L.S. Morales, MD, Heart Institute at Cincinnati Children's Hospital Medical Center, 3333 Burnet Ave, MLC 2004, Cincinnati, OH 45229 (E-mail: David.Morales@cchmc.org).

J Thorac Cardiovasc Surg 2020;159:1528-9

$0022-5223 / \$ 36.00$

Copyright (c) 2019 by The American Association for Thoracic Surgery

https://doi.org/10.1016/j.jtcvs.2019.10.207

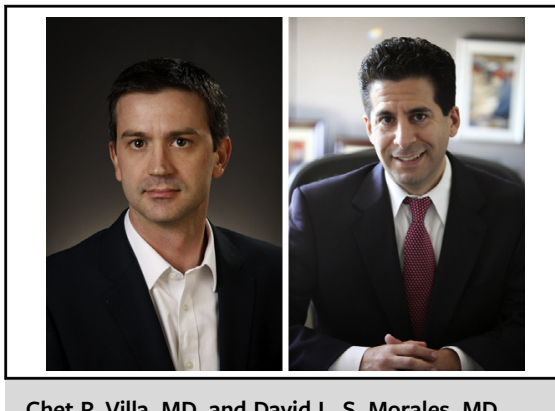

Chet R. Villa, MD, and David L. S. Morales, MD

CENTRAL MESSAGE

Modified operating conditions of

continuous-flow ventricular

assist devices in children may

have clinical implications.

conditions that they describe have little resemblance to the implant conditions and modifications required to implant the device in small children and patients with congenital heart disease. Furthermore, such factors as clinical condition at the time of implantation, arterial pressure, and anticoagulation management are more easily modified than RPM for a given patient and have been shown clinically to be associated with improved outcomes. ${ }^{2,5}$ Thus, the impact of the study on individual patient management is likely small, given the relatively narrow RPM range used for any given patient. Nonetheless, the study has potential broader implications for the field of pediatric VAD. To date, only 1 implantable continuous-flow VAD (the HVAD) is available that is small enough to be placed in most children. The device was rapidly deployed in the field off-label, with little preclinical data regarding the operating characteristics of the devices under "pediatric conditions." Ultimately, the clinical outcomes were reassuring; however, this study underscores a familiar refrain in pediatrics, "children are not small adults." The authors do believe that industry is now engaged with pediatric caregivers to maximize the use and outcomes of these devices in adolescents and preteens because of our pediatric learning network, ACTION, and its quality improvement initiatives. The pediatric VAD field, once a tortoise, is now a hare, because of our abandonment of competition and commitment to collaboration. 


\section{References}

1. Villa CR, Khan MS, Zafar F, Morales DLS, Lorts A. United States trends in pediatric ventricular assist implantation as bridge to transplantation. ASAIO J. 2017; 63:470-5.

2. Morales DLS, Rossano JW, VanderPluym C, Lorts A, Cantor R, St Louis JD, et al; Pedimacs Investigators. Third Annual Pediatric Interagency Registry for Mechanical Circulatory Support (Pedimacs) Report: preimplant characteristics and outcomes. Ann Thorac Surg. 2019;107: 993-1004.

3. VanderPluym CJ, Adachi I, Niebler R, Griffiths E, Fynn-Thompson F, Chen S, et al. Outcomes of children supported with an intracorporeal continuous-flow left ventricular assist system. J Heart Lung Transplant. 2019;38:385-93.

4. Graneger M, Thamsen B, Schloglhofer T, Lach S, Escher A, Haas T, et al. Blood trauma potential of the HeartWare Ventricular Assist Device in pediatric patients. J Thorac Cardiovasc Surg. 2020;159:1519-27.e1.

5. Milano CA, Rogers JG, Tatooles AJ, Bhat G, Slaughter MS, Birks EJ, et al ENDURANCE Investigators. HVAD: The ENDURANCE Supplemental Trial. JACC Heart Fail. 2018;6:792-802. 